\title{
Hydrolysis of xylans by enzyme systems from solid cultures of Trichoderma harzianum strains
}

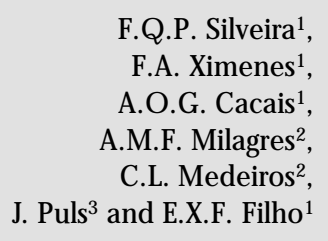

F.Q.P. Silveira ${ }^{1}$

F.A. Ximenes ${ }^{1}$,

A.O.G. Cacais ${ }^{1}$,

A.M.F. Milagres²,

C.L. Medeiros ${ }^{2}$,

J. Puls ${ }^{3}$ and E.X.F. Filho ${ }^{1}$

\author{
${ }^{1}$ Laboratório de Enzimologia, Departamento de Biologia Celular, \\ Universidade de Brasília, Brasília, DF, Brasil \\ ${ }^{2}$ Departamento de Biotecnologia, Faculdade de Engenharia Q uímica de Lorena, \\ Lorena, SP, Brasil \\ IInstitut für Holzchemie, H amburg, Germany
}

\section{Correspondence \\ Edivaldo X. Ferreira Filho \\ Laboratório de Enzimologia \\ Departamento de Biologia Celular \\ Universidade de Braślia \\ 70910-900 Brasília, DF \\ Brasil}

Research supported by the International Foundation for Science (IFS, Sweden), FAPDF and PADCT III (CNPq). Publication supported by FAPESP.

Received December 11, 1998 Accepted May 11, 1999

\section{Abstract}

Xylanase activity was isolated from crude extracts of Trichoderma harzianum strains $\mathrm{C}$ and 4 grown at $28^{\circ} \mathrm{C}$ in a solid medium containing wheat bran as the carbon source. Enzyme activity was demonstrable in the permeate after ultrafiltration of the crude extracts using an Amicon system. The hydrolysis patterns of different xylans and paper pulps by xylanase activity ranged from xylose, xylobiose and xylotriose to higher xylooligosaccharides. A purified B-xylosidase from the Trichoderma harzianum strain released xylose, xylobiose and xylotriose from seaweed, deacetylated, oat spelt and birchwood xylans. The purified enzyme was not active against acetylated xylan and catalyzed the hydrolysis of xylooligosaccharides, including xylotriose, xylotetraose and xylopentaose. However, the enzyme was not able to degrade xylohexaose. Xylanase pretreatment was effective for hardwood kraft pulp bleaching. Hardwood kraft pulp bleached in the XEOP sequence had its kappa number reduced from 13.2 to 8.9 and a viscosity of 20.45 cp. The efficiency of delignification was $33 \%$.

Xylan, the most abundant of the hemicelluloses in plant cell walls, has a linear backbone structure consisting of $\beta-1,4-$ linked xylosyl residues that, depending on its origin, may contain branches of L-arabinofuranosyl, acetyl, glucuronosyl and 4-Omethylglucuronosyl residues (1-4). Xylanase (1,4-ß-xylan xylanohydrolase; EC 3.2.1.8) and xylosidase (1,4- $\beta$-xylan xylohydrolase; EC 3.2.1.37) are main-chain hemicellulases that catalyze hydrolysis of xylans from different sources $(1,2,5)$. Most of the $\beta$-xylanases hydrolyze glycosidic linkages along the xylan backbone in a random cleavage mech-

\section{Key words}

- Trichoderma

- Xylan

- Xylanase anism, while $\beta$-xylosidases release $\mathrm{D}$-xylose from short-chain xylooligomers (1).

Many microorganisms produce xylandegrading enzyme activities. Among fungi, strains of Trichoderma spp have attracted considerable attention as rich sources of xylanolytic enzymes (5). Attempts to use xylanases as processing aids in the pulp and paper industry have the advantage of eliminating the use of chlorine in bleaching and decreasing the concentration of chlorinated organic compounds in the effluent (6).

Solid culture has been shown to be an efficient technique in the production of $x y$ - 
lan-degrading enzymes (7). According to Considine and Coughlan (7), some advantages of the use of solid cultivation over liquid procedure are: lower costs, improved enzyme stability, mimicking to some extent the natural habit of the fungus, production of enzymes with higher specific activities, generation of a protein-enriched byproduct, and easier downstream processing of the enzymes produced. In this paper, we report on the enzyme-catalyzed hydrolysis of various xylans and pulps by some xylan-degrading activities from solid cultures of T. harzianum strains $\mathrm{C}$ and 4 . We also describe some hydrolytic activities of a purified $\beta$-xylosidase from $T$. harzianum strain $C$ against xylans and xylooligomers.

Kraft and sulfite pulps for the experiments concerning hydrolysis products were from Modobirch (Hussum, Sweden) and Zellstoffabrik Rosenthal (Blankenstein, Germany), respectively. Oat spelt and birchwood xylans were from The Carl Roth Co. (Karlsruhe, Germany). Deacetylated and acetylated xylans were obtained by dimethylsulfoxide (DMSO) extraction of beechwood and wheat straw holocelluloses, respectively (3). Xylan (commonly called dilisk or dulse), extracted by $\mathrm{HCl}$ from the seaweed Palmaria palmata, was a gift from Maria G. Tuohy (University College, Galway, Ireland). Xylooligosaccharides were prepared as described before (8). Unbleached hardwood kraft pulp was provided by Bahia Sul Co. (Brasil). All other chemicals were analytical grade or equivalent. The experiments described below were carried out in triplicate.

The aerobic mesophilic T. harzianum strains $\mathrm{C}$ and 4 (CNP 17) were kindly provided by Cirano J. Ulhoa (Universidade Federal de Goiás, Brazil) and Itamar S. de Melo (CNPMA, Embrapa, Jaquariúna, Brazil), respectively. For production of xylan-degrading enzyme activities, the fungi were cultured at $28^{\circ} \mathrm{C}$ for 7 days in a solid medium containing wheat bran (9-11). Aliquots of the crude extracts of T. harzianum strains $\mathrm{C}$ and 4 were concentrated by ultrafiltration in an Amicon system using a membrane cutoff size of $10 \mathrm{kDa}$. The purification of $\beta-$ xylosidase activity was described in a previous publication (11).

Protein concentrations were determined by the method of Bradford (12) using bovine serum albumin as a standard. Assays measuring the release of reducing sugar from xylan $(1 \%, w / v)$ were performed as described in previous papers $(11,13)$.

The reaction mixtures containing $100 \mu 1$ of enzyme solution ( $3.73 \mu \mathrm{g}$ of protein from the ultrafiltrate of $T$. harzianum strain $\mathrm{C}$ or $1.6 \mu \mathrm{g}$ of protein from the ultrafiltrate of $T$. harzianum strain 4) and $500 \mu 1$ of $0.2 \%$ xylan in distilled water were incubated for $16 \mathrm{~h}$ at $28^{\circ} \mathrm{C}$ with shaking at $100 \mathrm{rev} / \mathrm{min}$. Kraft and sulfite pulps were hydrolyzed with $186.5 \mu \mathrm{g}$ of protein from the ultrafiltrate of T. harzianum strain $\mathrm{C}$ or $80 \mu \mathrm{g}$ of protein from the ultrafiltrate of $T$. harzianum strain 4 and $1.0 \mathrm{~g}$ of pulp in distilled water, in a reaction mixture of $5.0 \mathrm{ml}$ at $40^{\circ} \mathrm{C}$ with shaking for $18 \mathrm{~h}$ at $80 \mathrm{rev} / \mathrm{min}$. The reaction was stopped by heating in boiling water and the preparations were centrifuged at $3,000 \mathrm{~g}$ for 5 and $10 \mathrm{~min}$, respectively. The hydrolysis products were determined by high performance anion exchange chromatography coupled with pulsed amperometric detection (Dionex Corp., Sunnyvale, CA, USA), as described previously $(3,14,15)$. The hydrolysis products of xylans and xylooligomers with $8.85 \mu \mathrm{g}$ of purified $\beta$-xylosidase were analyzed as described above. However, the hydrolysis of xylooligomers was determined after 1 to $2 \mathrm{~h}$ of incubation at $40^{\circ} \mathrm{C}$.

Pulp properties were analyzed according to the standard methods of the Technical Association of the Pulp and Paper Industry (TAPPI, Atlanta, GA, USA). Kappa number was determined by TAPPI test method T236 os-76. The kappa number is defined as the amount $(\mathrm{ml})$ of a $0.1 \mathrm{~N} \mathrm{KMnO}_{4}$ solution consumed by $0.5-1.0 \mathrm{~g}$ of moisture-free pulp 
under standard conditions. The viscosity of the pulp was determined by dissolving delignified pulp in cupriethylenediamine and measuring the viscosity of a $0.5 \%$ solution at $25^{\circ} \mathrm{C}$ in a capillary viscometer (TAPPI T230 su-63). The efficiency of delignification (ED) is given by the following equation: $\mathrm{ED}$ $(\%)=$ unbleached kappa number - kappa number after treatment x 100/initial kappa number.

Selectivity is defined as the relation between efficiency of delignification and \% reduction in pulp viscosity.

A dried unbleached hardwood kraft pulp produced in an industrial pulp mill had an initial kappa number, consistency and viscosity of $13.2,36 \%$ and $31.0 \mathrm{cp}$, respectively. Each gram of pulp was treated with 2 IU of xylanase in a double-layer polyester bag for $3 \mathrm{~h}$ in $50 \mathrm{mM}$ sodium acetate buffer, $\mathrm{pH} 5.0-6.0$, at $50^{\circ} \mathrm{C}$ at a consistency of $10 \%$ ( $10 \mathrm{~g}$ dry mass pulp/100 $\mathrm{ml}$ water). After the enzyme treatment $(\mathrm{X})$, the pulp samples were washed with distilled water and used in the following treatment sequence: E-O-P. The pulp (20 g dry weight) was subjected to alkali treatment (E) at $10 \%$ consistency with $1.8 \mathrm{~g} \mathrm{NaOH} / 100 \mathrm{~g}$, and $0.1 \mathrm{M}$ magnesium sulfate was added. Oxygen delignification of the pulp (O) was carried out in the pulp mill at $6 \mathrm{kgf} / \mathrm{cm}^{2}$ oxygen pressure and $100^{\circ} \mathrm{C}, \mathrm{pH}$ 11 , for $1 \mathrm{~h}$. The pulp was then treated with $0.5 \%$ hydrogen peroxide $(\mathrm{P})$ under the same conditions as described above. After completion of the bleaching sequence, the pulp was thoroughly washed with distilled water. Again, the pulp in the control sequence was submitted to the same treatment with no enzyme added.

Screening of nine Trichoderma harzianum strains grown by solid-state fermentation on media containing wheat bran as the carbon source showed that the best balance of xylan-degrading enzyme activity was obtained from cultures of strain 4 (9). The hydrolysis products of xylans and paper pulps by xylan-degrading enzyme activities from the ultrafiltrates of $T$. harzianum strains $\mathrm{C}$ and 4 were determined by high performance liquid chromatography (Figure 1). Neither of these enzyme samples was able to degrade cellulose, indicating a possible application in biobleaching processes. A comparison was made of the enzymatic hydrolysis of oat spelt, birchwood, seaweed, acetylated and deacetylated xylans and sulfite and Kraft pulps. The two enzyme samples showed some differences in the range and amounts of xylose and intermediate products (xylobiose, xylotriose, xylotetraose, xylopentaose and xylohexaose) released from the substrates (Figure 1). The enzyme sample from T. harzianum strain $\mathrm{C}$ showed low activity against oat spelt, birchwood, seaweed and acetylated xylans. Xylotriose and xylohexaose were the main products. The behavior of this xylanase activity on different xylans as substrate resembles that of an endoenzyme mechanism. On the other hand, the hydrolysis of sulfite and kraft pulps was followed by release of high amounts of xylose, indicating that this enzyme activity switched from an endo- to an exo-mode of action. However, we cannot discard the hypothesis that the large amounts of xylooligosaccharide accumulation could lead to their breakdown to the end products of digestion, probably $\mathrm{xy}-$ lose and xylobiose. Xylotetraose and xylohexaose were the major products generated from deacetylated xylan by xylanase activity from T. harzianum strain C. On the other hand, the small amount of hydrolysis products (xylotriose and xylohexaose) released from acetylated xylan suggests that the presence of acetyl residues as side chains limited the action of xylanase activity $(4,10)$. Small amounts of xylopentose were liberated from oat spelt, birchwood, seaweed and acetylated xylans by xylanase activity from $T$. harzianum strain 4 . The enzyme removed xylose from all xylans, suggesting an exoenzyme activity. Alternatively, this could also indicate that the xylan-degrading enzymes are highly active and thus break down the 

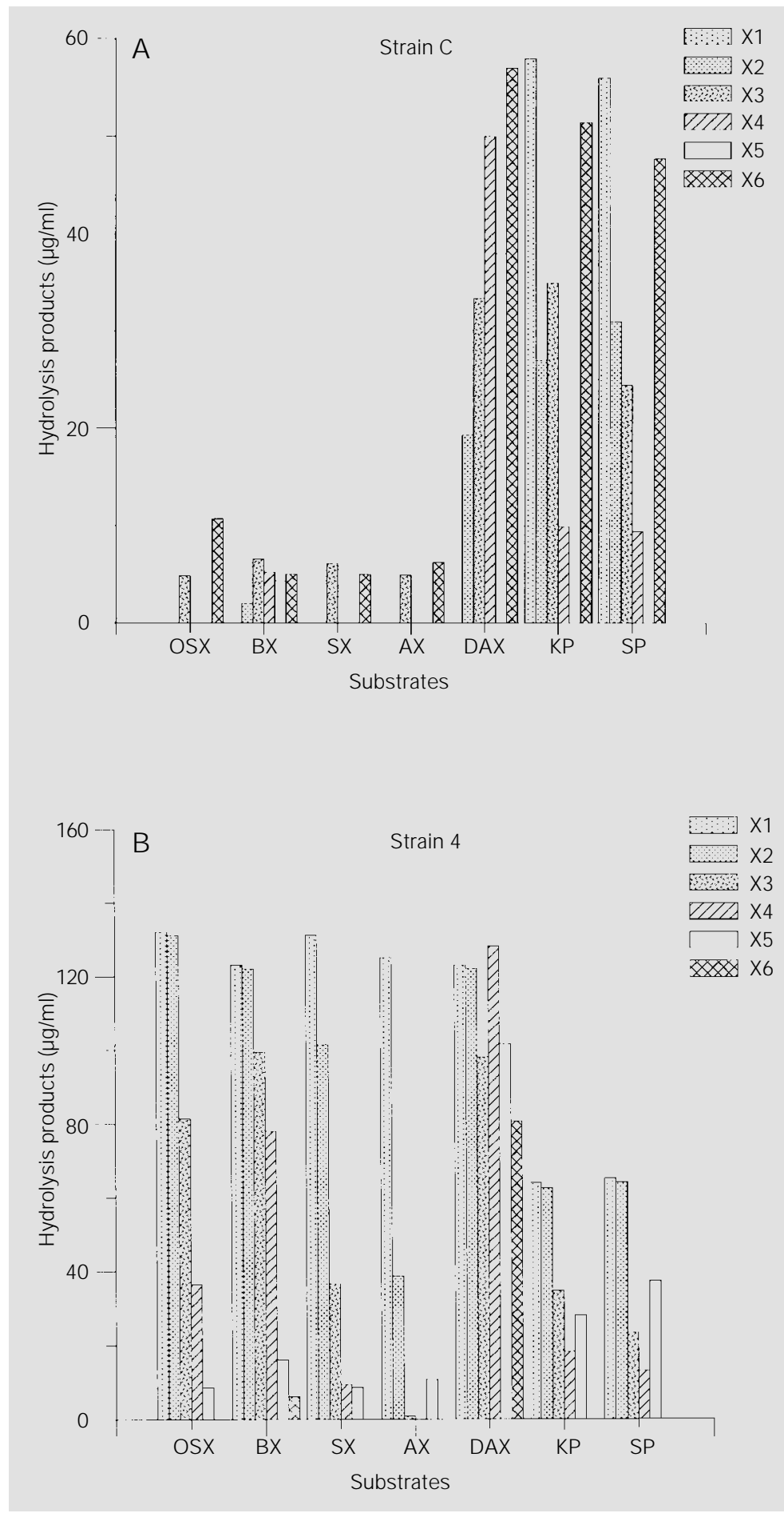

Figure 1 - Hydrolysis products of xylans and paper pulps by xylanase activity from the ultrafiltrate of Trichoderma harzianum strain $C(A)$ and strain 4 (B). X1, Xylose; $X 2$, xylobiose; $X 3$, xylotriose; $X 4$, xylotetraose; $X 5$, xylopentaose; $X 6$, xylohexaose; OSX, oat spelt xylan; BX, birchwood xylan; SX, seaweed xylan; AX, acetylated xylan; DAX, deacetylated xylan; KP, kraft pulp; SP, sulfite pulp. Assay conditions were given in the text. released xylooligosaccharides to their limit products. The predominant product from deacetylated xylan hydrolysis was xylotetraose. The xylanase activity yielded mainly xylose, xylobiose and xylotriose from birchwood xylan. The major hydrolysis products of kraft and sulfite pulps were xylose and xylobiose.

A purified $\beta$-xylosidase activity from $T$. harzianum strain C (11) was also tested against various xylans (data not shown). The enzyme showed little activity against xylans. It produced xylose exclusively from oat spelt and seaweed xylans. No arabinose was detected among the hydrolysis products of oat spelt xylan. $\beta$-Xylosidase had no action against acetylated xylan, suggesting the presence of steric hindrance. The addition of an acetyl xylan esterase activity would be crucial for the efficient hydrolysis of this substrate $(1,4,13)$. When a mixture containing acetylated xylan fragments from the steaming extract of birchwood, xylanase and xylosidase activities was supplemented with acetyl xylan esterase, it enhanced xylose production (1). In contrast to acetylated $x y-$ lan, hydrolysis of deacetylated xylan was accompanied by the release of xylose and xylobiose. Hydrolysis products released by purified ß-xylosidase from birchwood xylan breakdown were xylose, xylobiose and xylotriose. The mode of action against unsubstituted xylooligomers was also analyzed by HPLC. B-Xylosidase was not able to degrade xylohexaose. The hydrolytic capacity of $\beta$-xylosidase activity is generally reported to decrease towards longer xylooligomers $(2,4)$. The hydrolysis of xylotriose during different periods of incubation produced exclusively xylobiose. This result suggests that xylobiose was produced by a transglycosidase mechanism. The enzyme also showed transferase activity with xylotetraose and xylopentaose as substrates. Transferase activity has been described for xylan-degrading enzymes of fungi $(2,13,15)$. The hydrolysis pattern of xylotetraose was 
quite similar during 1- and 2-h incubation. Xylotetraose was split into xylose, xylotriose and xylopentaose. Xylobiose and xylohexaose were the only hydrolysis products of xylopentaose after 1-h incubation, whereas xylose was also produced after a 2 -h period of incubation.

The effect of xylanase activity from a cellulase-free ultrafiltrate sample of $T$. harzianum strain 4 on unbleached hardwood kraft pulp is described in Table 1. A reduction in hardwood kraft pulp kappa number after xylanase treatment was larger compared to the control sequence (without the enzyme stage). When xylanase treatment was applied, a moderate viscosity drop was obtained, indicating that there was little or no cellulose depolymerization and a selective removal of xylan (16-18). The enzyme sample improved the delignification of unbleached hardwood kraft pulp, thus reducing the amount of active chlorine required to obtain a given pulp brightness effect $(6,16)$. The process of lignin release by xylan removal and the further increased swelling of the fiber walls could explain this effect $(6,16)$. In comparison to a thermostable xylanase from Thermomonospora fusca KW 3 (19), xylanase activity from $T$. harzianum strain
Table 1 - Effect of T. harzianum strain 4 xylanase activity on pulp bleaching.

The unbleached pulp had kappa number of 13.2 and viscosity of $31.0 \mathrm{cp}$ before treatment. apulp prebleaching. bpulp bleaching followed by alkaline, oxygen and hydrogen peroxide treatments.

\begin{tabular}{lcccc}
\hline Samples & Kappa no. & Viscosity & $\begin{array}{c}\text { Efficiency of } \\
\text { delignification (\%) }\end{array}$ & Selectivity \\
\hline Controla $^{\text {Ultrafiltrate }}$ & 12.8 & 29.3 & 3.0 & 0.54 \\
Control $^{b}$ & 12.2 & 29.21 & 8.0 & 1.4 \\
Ultrafiltrate $^{b}$ & 9.6 & 20.9 & 27.3 & 0.84 \\
& 8.9 & 20.45 & 33 & 0.96
\end{tabular}

4 produced a more extensive delignification of the pulp.

In conclusion, the xylan-degrading enzymes from $T$. harzianum strains 4 and $\mathrm{C}$ act mainly on $\beta-1,4$ xylosidic linkages. The presence of substituents limits the access of these enzymes to the main chain of xylan. The purified $\beta$-xylosidase activity has transferase as well as hydrolase activities. The introduction of a xylanase preparation from $T$. harzianum strain 4 as one bleaching stage facilitated the subsequent bleaching of hardwood kraft pulp.

\section{Acknowledgments}

The technical assistance of Mrs. Annegret Borchmann is gratefully acknowledged.

\section{References}

1. Puls J \& Poutanen K (1989). Mechanisms of enzymic hydrolysis of hemicelluloses (xylans) and procedures for determination of the enzymic activities involved. In: Coughlan MP (Editor), Enzyme System for Lignocellulose Degradation. Elsevier Applied Science, London, 151-165.

2. Coughlan MP, Tuohy MG, Filho EXF, Puls J, Clayessens M, Vrsanská M \& Hughes MM (1993). Enzymological aspects of microbial hemicellulases with emphasis on fungal systems. In: Coughlan MP \& Hazlewood GP (Editors), Hemicellulose and Hemicellulases. Portland Press, London, 53-84.

3. Puls J \& Schuseil J (1993). Chemistry of hemicelluloses: relationship between hemicellulose structure and enzymes required for hydrolysis. In: Coughlan MP \&
Hazlewood GP (Editors), Hemicellulose and Hemicellulases. Portland Press, London, 1-27.

4. Filho EXF (1994). The xylan-degrading enzyme system. Brazilian J ournal of Medical and Biological Research, 27: 1093-1109.

5. Wong KKY \& Saddler J N (1992). Trichoderma xylanases, their properties and applications. In: Visser J, Beldman G, Kusters-van Someren M A \& Voragen AG] (Editors), Xylans and Xylanases. Elsevier, Amsterdam, 171-186.

6. Filho EXF (1998). Hemicellulases and biotechnology. In: Pandalai SG (Editor), Recent Research Developments in Microbiology. Research Signpost, India, 165-176.

7. Considine PJ \& Coughlan MP (1989). Production of carbohydrate-hydrolysing enzyme blends by solid-state fermentation.
In: Coughlan MP (Editor), Enzyme System for Lignocellulose Degradation. Elsevier Applied Science, London, 273-281.

8. Puls J, Borchmann A, Gottschalk D \& Wiegel J (1988). Xylose and xylooligomers. Methods in Enzymology, 160: 528536.

9. Silveira FQP, Melo IS \& Filho EXF (1997). Carbohydrate-hydrolysing enzyme activity production by solid-state cultures of Trichoderma harzianum strains. Revista de Microbiologia, 28: 152-156.

10. Filho EXF (1996). Purification and characterization of a B-glucosidase from solidstate cultures of Humicola grisea var. thermoidea. Canadian J ournal of Microbiology, 42: 1-5.

11. Ximenes FA, Silveira FQP \& Filho EXF (1996). Production of ß-xylosidase activity 
by Trichoderma harzianum strains. Current Microbiology, 33: 71-77.

12. Bradford MM (1976). A rapid and sensitive method for the quantitation of microgram quantities of protein utilizing the principle of protein dye binding. Analytical Biochemistry, 72: 248-254.

13. Filho EXF, Puls J \& Coughlan MP (1993). Biochemical characteristics of two endoß-1,4-xylanases produced by Penicillium capsulatum. J ournal of Industrial Microbiology, 11: 171-180.

14. Puls J , Tenkanen M, Korte HE \& Poutanen K (1991). Products of beechwood acetyl4-O-methylglucuronoxylan hydrolysis by a xylanase and an acetylxylanesterase. Enzyme and Microbial Technology, 13: 483486.

15. Tenkanen M, Puls J \& Poutanen K (1992). Two major xylanases of Trichoderma reesei. Enzyme and Microbial Technology, 14: 566-574.

16. Tremblay $L \&$ Archibald F (1993). Production of a cloned xylanase in Bacillus cereus and its performance in kraft pulp prebleaching. Canadian J oumal of Microbiology, 39: 853-860.

17. Bajpai $P$ (1997). Microbial xylanolytic enzyme system: properties and applications. Advances in Applied Microbiology, 43:
141-194.

18. Ragauskas AJ , Poll KM \& Cesterino AJ (1994). Effects of xylanase pretreatment procedures on nonchlorine bleaching. Enzyme and Microbial Technology, 16: 492495.

19. Davis S, Gysin B, Casimir J \& Zimmermann W (1992). Thermostable xylanases from actinomycetes for pulp bleaching. In: Visser J, Beldman G, Kusters-van Someren MA \& Voragen AGJ (Editors), Xylans and Xylanases. Elsevier, Amsterdam, 551-554. 